\title{
Giardia duodenalis Genotyping from Dogs and Cats in Brazil: A Reality Still Unknown
}

\author{
Phelipe Austriaco-Teixeira, Luiz Antonio Pimentel Lopes de Oliveira and Maria Fantinatti* \\ Laboratório Interdisciplinar de Pesquisas Médicas, Instituto Oswaldo Cruz - FIOCRUZ, Brazil
}

Submission: February 28, 2019; Published: March 07, 2019

*Corresponding author: Maria Fantinatti, Laboratório Interdisciplinar de Pesquisas Médicas, Instituto Oswaldo Cruz - FIOCRUZ, Rio de Janeiro/RJ, CEP 21040-360, Brazil

\section{Mini Review}

Giardia duodenalis is possibly the first known intestinal protozoan in man. However, there are still many issues to be understood, especially in the field of taxonomy, which, with molecular studies, have presented great advances in understanding the epidemiological characteristics of $G$. duodenalis infection. Giardiasis is considered a zoonosis of public health importance, since G. duodenalis can infect a broad spectrum of mammalian hosts, including humans and domestic animals $[1,2]$. Thus, measures to control giardiasis should consider the participation of animals in the transmission cycles [3]. Currently the G. duodenalis species is divided into eight assemblages, classified in A-H [1,2]. The $G$. duodenalis assemblages $\mathrm{C}$ and $\mathrm{D}$ are still considered host-specific for canines and the assemblage $\mathrm{F}$ for cats, although they have already been observed in other animal species [4-6]. Assemblages $\mathrm{A}$ and $\mathrm{B}$ get more prominence because they have high zoonotic potential and can be found in humans and other mammalian hosts, including dogs and cats. As interest in domestic animals has grown in recent years and we have observed a growing humanization of dogs and cats, the existence of assemblages with affinity for humans and domestic animals (A and B) may support the occurrence of anthropozoonotic cycles inside the household $[2,7]$.

In order to verify the distribution of $G$. duodenalis assemblages in companion animals in Brazil, we conducted a review based on an exploratory and descriptive bibliographic survey on the twenty-first of February 2019, with the main theme: "Giardia duodenalis assemblages circulating in dogs and cats in Brazil". It was used the electronic database Medical Literature Analysis and Retrieval Sistem on-line (Medline). They were used as MeSH terms to delimit the search for:
a. host: "dog" or "cat" or "pet";
b. Etiological agent: "Giardia";
c. Geographical area: "Brazil”.

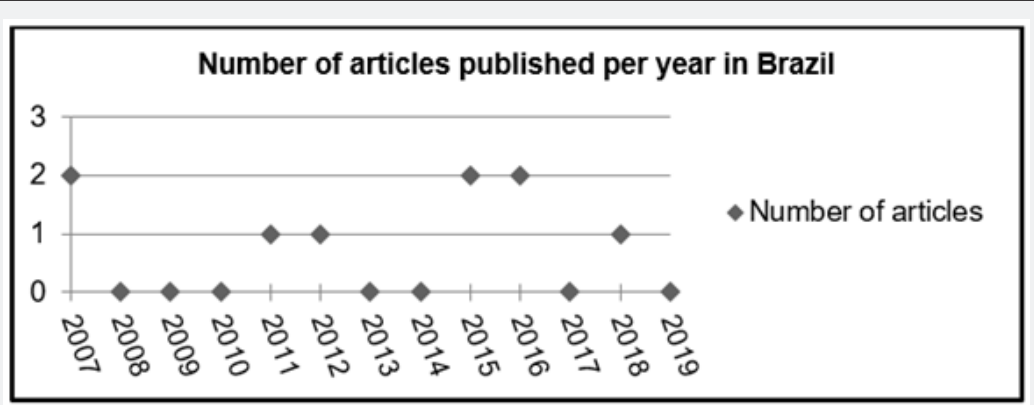

Figure 1: Number of articles published in Medical Literature Analysis and Retrieval Sistem on-line per year that address genotyping of Giardia duodenalis isolates from faeces samples from dogs and cats in Brazil.

To combine terms, we used standard Boolean operators. We obtained the following search strategy: ((c(dog or cat) or pet) AND Giardia) AND (assemblage OR genotype)) AND brazil. For the selection of manuscripts was used as inclusion criteria: articles retrieved in full and articles published in english. Twelve articles were found published. Two studies were excluded because genotyped a single $G$. duodenalis strain for laboratory experiments and one study did not succeed in 
the gene amplification and genotyping of the isolates from fecal animal samples. Among the selected studies, seven carried out genotyping of $G$. duodenalis isolated from only dog samples and two from dog and cat samples. The low number of studies found highlight show that the distribution of $G$. duodenalis assemblages in Brazil still poorly understood. The study of dog and cat samples genotyping in Brazil is recent, the first one was carried out in 2007 [8]. And there is a low frequency of publications on the subject per year (Figure 1).

The genotyping tools used are still limited to establishing transmission routes. The main methodology used for genotyping was gene sequencing that was addressed in 8/9 articles found in this review [8-15]. The PCR-RFLP was used in three articles $[10,11,16]$, and was used as a single characterization methodology in only one study [16]. For G. duodenalis genotyping, the following gene targets were used: $\beta$-gia, gdh and tpi. In Brazil, studies until the year 2011 used a single gene for characterization and from 2012 studies became multi-locus. The use of more than one gene is recommended, however it is not uncommon to observe different groupings between the targets used [2].

The Brazilian territory is composed of 26 states and a federal district, distributed in five regions (North, Northeast, Midwest, Southeast and South) (Figure 2). Of the nine studies selected in this review using dogs feces samples, two were performed in the Southern region (Paraná and Santa Catarina) and seven in the Southeast region (four in São Paulo, two in Rio de Janeiro and one in Minas Gerais). The other 21 states and the federal district still lack studies on the subject. In $G$. duodenalis isolates from the dog samples, assemblages A, B, C, D or E were found. In São Paulo, studies from 2007 and 2012 identified, using the $g d h$ gene, only the host-specific assemblage (C and D) in domestic, wandering or kennel dogs $[9,11]$. However, Volotão and co-workers using the $\beta$-gia gene in 2011 reported only circulation of assemblage A. Although the stool samples were obtained in the same state, the sample collection site is about $450 \mathrm{~km}$. The study by David [13] corroborates the circulation of assemblage with zoonotic (A) and non-zoonotic (C and D) potential in São Paulo.

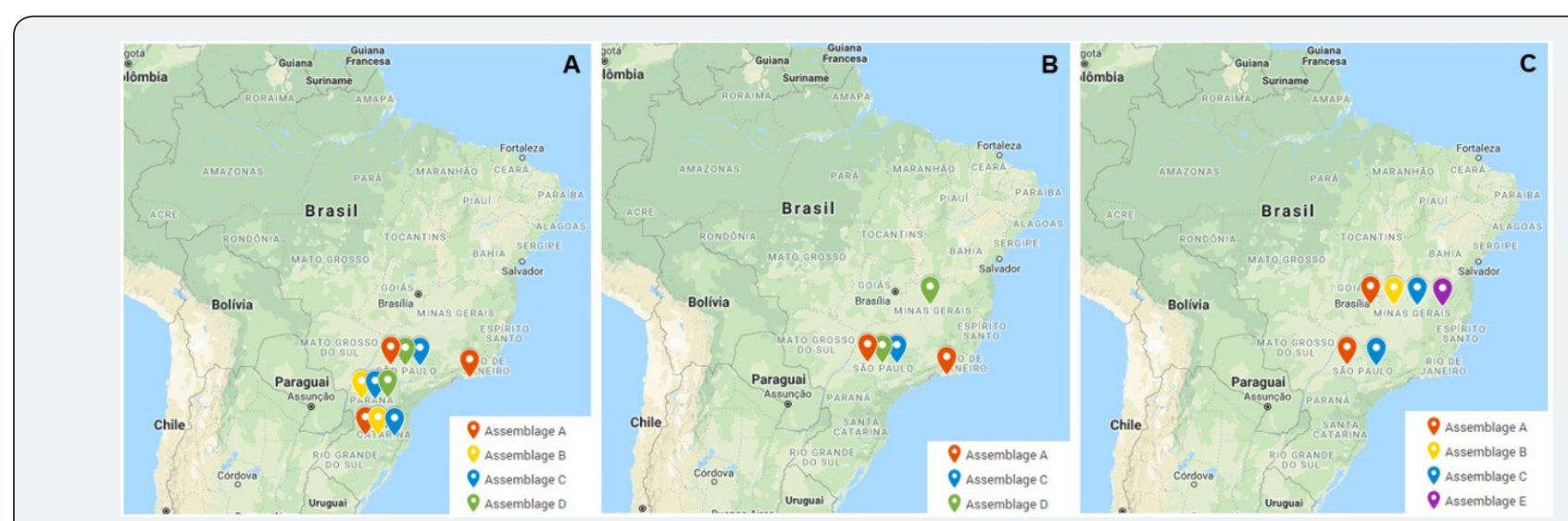

Figure 2: Illustrative map of the Giardia duodenalis assemblage's distribution from dogs in Brazil, according to the target used for genotyping. A: G. duodenalis genotyping using gdh target; B: G. duodenalis genotyping using $\beta$-gia target; C: G. duodenalis genotyping using tpi target. The balloons are classified by color according to the assemblage. Orange: assemblage A; Yellow: assemblage B; Blue: assemblage C; Green: assemblage D; Purple: assemblage E.

In Rio de Janeiro, Volotão et al. [8] verified the assemblage A infecting dogs and, after 11 years, Fantinatti \& collaborators [15] verified circulation of the same assemblage, suggesting the maintenance of this assemblage in the environment. The only study carried out in Santa Catarina identified the circulation of assemblages A, B and C in dogs by PCR-RFLP (gdh target) [16]. The other study carried out in the Southern region, Paraná, using the $g d h$ and $\beta$-gia gene targets, verified the circulation of assemblages B, C and D [12]. The identification of assemblages with zoonotic potential found by the authors in dogs and in humans suggests that anthropozoonotic cycles may be occurring within household.

The G. duodenalis genotyping from dogs of commercial kennels in Minas Gerais using the $g d h$ target identified the assemblage D circulating among the animals. However, the data were not corroborated by tpi target, in which the sequences were grouped in assemblages A, B, C and E, and none in assemblage
D. Identification of host-specific assemblages for canines at dog agglomeration sites points to the possibility of dissemination among all the animals of the place. Since G. duodenalis infection can lead to compromised animal health, the circulation of this protozoan in commercial kennels can have an economic impact, where animals are sold mainly puppies. On the other hand, dogs acquired and infected by zoonotic assemblages raises the possibility of carrying Giardia cysts to the residence and promoting transmission routes between their owner and other animals of the household.

The two genotyping studies of $G$. duodenalis isolates from cat specimens date back to 2007, demonstrating that there have been no studies on the subject in Brazil for more than a decade $[8,9]$. Both were concentrated in the Southeast region (Rio de Janeiro and São Paulo), demonstrating a lack of knowledge about the genotypes of $G$. duodenalis circulating in cats in the other four regions of Brazil. Volotão \& collaborators [8] genotyped a single 
cat sample from Rio de Janeiro and identified genotype A, while in São Paulo, Souza [9] described the circulation of genotypes $\mathrm{A}$ and $\mathrm{F}$ in 19 cats. Both studies highlight the possibility of anthropozootic cycles, since samples of dogs, humans or cattle parasitized with G. duodenalis of genotype A were also evaluated.

The literature review indicates there is no possible to determine the epidemiology of $G$. duodenalis assemblages in domestic animals in Brazil, mainly in cats, because the studies are scarce, punctual and characterize a low number of samples. The few territories studied are concentrated in the regions with the highest Human Development Index in the country and demonstrate the circulation of assemblages with zoonotic potential. Since giardiasis is a disease that can cause harm to companion animals and their owners, it is essential that more studies be carried out in Brazil in order to elucidate how the zoonotic transmission route of $G$. duodenalis in different regions of the country behaves.

The elucidation of assemblages and zoonotic transmission routes could promote new measures aimed at prophylaxis and the treatment of giardiasis in the veterinary and public health field. Thus, the identification of transmission routes of the parasite represents a strategic tool to reduce the giardiasis incidence in the country, as well as to save costs related to treatment and, above all, to guarantee the life quality of humans and animals.

\section{Acknowledgement}

Phelipe Austriaco-Teixeira and Luiz Antonio Pimentel Lopes de Oliveira contributed equally to the production of the manuscript.

\section{References}

1. Adam RD (2001) Biology of Giardia lamblia. Clin Microbiol Rev 14: 447-475.

2. Feng Y, Xiao L (2011) Zoonotic potential and molecular epidemiology of Giardia species and giardiasis. Clin Microbiol Rev 24: 110-140.

3. Fantinatti M (2019) Zoonotic potential of Giardia lamblia and control of giardiasis. Insights in Veterinary Science 3: 1-4.

4. Mayrhofer G, Andrews RH, Ey PL, Chilton NB (1995) Division of Giardia isolates from humans into two genetically distinct assemblages by electrophoretic analysis of enzymes encoded at 27 loci and comparison with Giardia muris. Parasitology 111: 11-17.
5. Hopkins RM, Meloni BP, Groth DM, Wetherall JD, Reynoldson JA, et al. (1997) Ribosomal RNA sequencing reveals differences between the genotypes of Giardia isolates recovered from humans and dogs living in the same locality. J Parasitol 83: 44-51.

6. Monis PT, Andrews RH, Mayrhofer G, Mackrill J, Kulda J, et al. (1998) Novel lineages of Giardia intestinalis identified by genetic analysis of organisms isolated from dogs in Australia. Parasitology 116: 7-19.

7. Walsh F (2009) Human-animal bonds I: the relational significance of companion animals. Fam Process 48: 462-480.

8. Volotão AC, Costa-Macedo LM, Haddad FS, Brandão A, Peralta JM, et al. (2007) Genotyping of Giardia duodenalis from human and animal samples from Brazil using beta-giardin gene: a phylogenetic analysis. Acta Trop 102: 10-19.

9. Souza SL, Gennari SM, Richtzenhain LJ, Pena HF, Funada MR, et al. (2007) Molecular identification of Giardia duodenalis isolates from humans, dogs, cats and cattle from the state of São Paulo, Brazil, by sequence analysis of fragments of glutamate dehydrogenase ( $g \mathrm{dh}$ ) coding gene. Vet Parasitol 149: 258-264.

10. Volotão AC, Ramos NM, Fantinatti M, Moraes MV, Netto HA, et al. (2011) Giardiasis as zoonosis: between proof of principle and paradigm in the Northwestern region of São Paulo State, Brazil. Braz J Infect Dis 15: 382-383.

11. Paz e Silva FM, Monobe MM, Lopes RS, Araujo JP (2012) Molecular characterization of Giardia duodenalis in dogs from Brazil. Parasitol Res 110: 325-334.

12. Colli CM, Bezagio RC, Nishi L, Bignotto TS, Ferreira ÉC, et al. (2015) Identical assemblage of Giardia duodenalis in humans, animals and vegetables in an urban area in southern Brazil indicates a relationship among them. Plosone 10: e0118065.

13. David ÉB, Guimarães S, de Oliveira AP, Goulart de Oliveira-Sequeira TC, Nogueira Bittencourt G, et al. (2015) Molecular characterization of intestinal protozoa in two poor communities in the State of São Paulo, Brazil. Parasit Vectors 8: 103.

14. Fava NM, Soares RM, Scalia LA, Cunha MJ, Faria ES, et al. (2016) Molecular typing of canine Giardia duodenalis isolates from Minas Gerais, Brazil. Exp Parasitol 161: 1-5.

15. Fantinatti M, Caseca AC, Bello AR, Fernandes O, Da-Cruz AM (2018) The presence of Giardia lamblia assemblage A in dogs suggests an anthropozoonotic cycle of the parasite in Rio de Janeiro, Brazil. Infect Genet Evol 65: 265-269.

16. Quadros RM, Weiss PH, Marques SM, Miletti LC (2016) Potential crosscontamination of similar Giardia duodenalis assemblage in children and pet dogs in southern brazil, as determined by PCR-RFLP. Rev Inst Med Trop Sao Paulo 58: 66. 
Your next submission with Juniper Publishers will reach you the below assets

- Quality Editorial service

- Swift Peer Review

- Reprints availability

- E-prints Service

- Manuscript Podcast for convenient understanding

- Global attainment for your research

- Manuscript accessibility in different formats ( Pdf, E-pub, Full Text, Audio)

- Unceasing customer service

Track the below URL for one-step submission https://juniperpublishers.com/online-submission.php 